\title{
Night vision and glare vision thresholds and recovery time in myopic and hyperopic eyes
}

\author{
KP Mashige
}

Discipline of Optometry, School of Physiotherapy, Sport Science and Optometry, Faculty of Health Sciences, University of KwaZulu-Natal, Westville Campus, Private Bag X54001, Durban, 4000 South Africa

<mashigek@ukzn.ac.za>

Received 27 February 2010; revised version accepted 30 September 2010

\begin{abstract}
The purpose of this study was to compare night vision and glare vision thresholds and recovery times in myopic and hyperopic eyes. Using a Night Sight Meter, these three parameters were measured in 44 myopic and 44 hyperopic eyes of Black male subjects age-matched 20.8 years \pm 1.67 and 21.6 years \pm 1.05 old respectively and compared. Thresholds were measured first by assessing the eye's ability to see under conditions of low illumination and in the presence of a glare source. Glare recovery time was determined by measuring the minimum time needed to adjust to low levels of light illumination after exposure to a glare stimulus. Descriptive, two-sample $t$-test and Pearson correlation statistics were used to analyze and compare the sets of data from the two groups. The mean refractive error in the myopic eyes was $-2.15 \mathrm{D} \pm 1.41$ (range $=-0.50 \mathrm{D}$ to $-4.50 \mathrm{D}$ ) and $1.76 \mathrm{D} \pm 1.22$ (range $=0.50 \mathrm{D}$ to 4.00 $\mathrm{D})$ in the hyperopic group. The mean night vision thresholds for the myopic eyes was $32 \mathrm{~cd} / \mathrm{m}^{2} \pm 4.69$ (range $=23 \mathrm{~cd} / \mathrm{m}^{2}$ to $42 \mathrm{~cd} / \mathrm{m}^{2}$ ) and $28.97 \mathrm{~cd} / \mathrm{m}^{2} \pm$ $4.90\left(\right.$ range $=18 \mathrm{~cd} / \mathrm{m}^{2}$ to $\left.37 \mathrm{~cd} / \mathrm{m}^{2}\right)$ for hyperopic eyes. The difference between the mean night vision thresholds of the myopic and hyperopic eyes was statistically significant $(p<0.05)$. For glare vision
\end{abstract}

threshold, the mean for myopic eyes was $64 \mathrm{~cd} / \mathrm{m}^{2}$ $\pm 5.81\left(\right.$ range $=53 \mathrm{~cd} / \mathrm{m}^{2}$ to $\left.78 \mathrm{~cd} / \mathrm{m}^{2}\right)$, while the mean for hyperopic eyes was $44.84 \mathrm{~cd} / \mathrm{m}^{2} \pm 5.69$ (range $=32 \mathrm{~cd} / \mathrm{m}^{2}$ to $59 \mathrm{~cd} / \mathrm{m}^{2}$ ). Also, the difference between the mean glare vision thresholds of the myopic and hyperopic eyes was statistically significant $(p<0.05)$. The recovery times ranged from $0.45 \mathrm{~s}$ to $3.10 \mathrm{~s}$ for the myopic eyes and $0.30 \mathrm{~s}$ to $2.25 \mathrm{~s}$ for the hyperopic eyes. The mean glare recovery time for the myopic eyes (mean $=1.41 \mathrm{~s} \pm 0.77)$ was significantly longer $(p<$ 0.05 ) than the times for hyperopic eyes (mean $=1.04 \mathrm{~s} \pm 0.65)$. There was a significant positive correlation between recovery times and the magnitude of myopia $(r=0.93, p<0.05)$ while the relationship between recovery times and the magnitude of hyperopia was significantly negatively correlated $(r=-0.76, p<0.05)$. These findings suggest that myopic persons would have more difficulty seeing under conditions of low illumination and in the presence of glare than hyperopic eyes. This could probably be due to aberrations resulting from larger pupils in the myopic eyes. $(S$ Afr Optom 2010 69(3) 132-139)

Key words: Night vision threshold, glare vision threshold, glare recovery time, aberrations, myopia, hyperopia

BSc(Wits) BOptom(UDW) CAS(NewEnCo) MOptom(UKZN) 


\section{Introduction}

The sense of vision provides most of the information needed to perform daily tasks well and efficiently. However, given that many parameters of visual performance are compromised under conditions of low illumination ${ }^{1}$, certain tests have been designed to assess features of vision ranging from acuity at low light levels to glare resistance and recovery. The night vision threshold tests the minimum amount of illumination required by the subject to see the test target in low illumination, and the higher the night vision threshold, the poorer is the subject's night vision. Glare threshold is the extent to which the subject can still see objects while facing a source of glare such as light from the headlights of oncoming traffic at night. This threshold is measured by assessing the subject's night vision threshold in the presence of a glare source. As in the case with night vision threshold, the higher the glare threshold value, the poorer is the subject's ability to detect a test object under scotopic conditions in the presence of glare.

Glare is the disruption of vision produced by luminance within the visual field that is sufficiently greater than the luminance to which the eyes are adapted ${ }^{2}$. The main types of glare are disability (veiling) and discomfort glare 3 . Disability glare is due to excessive light in the visual field which causes poor visibility and therefore poor visual performance. This type of glare causes a veil of light over the fovea which changes its adaptation or sensitivity to visual stimuli without necessarily causing visual discomfort ${ }^{3}$.

Discomfort glare is caused when the eye is suddenly exposed to light of higher luminance than the source to which the eye is adapted and causes annoyance or discomfort without necessarily impairing the ability to see detail 3 . Discomfort glare (Dg) from a source of light can be expressed by the equation ${ }^{3}$ :

$$
\mathrm{Dg}=\frac{\mathrm{B}_{\mathrm{S}}^{1.6} \times \mathrm{W}^{0.8} \times 0.478}{\mathrm{~B}_{\mathrm{B}} \times \mathrm{P}^{1.6}}
$$

where $B_{S}=$ luminance of source $\left(\mathrm{cd} / \mathrm{m}^{2}\right), B_{B}=1 u$ minance of background $\left(\mathrm{cd} / \mathrm{m}^{2}\right), \mathrm{W}=$ angular size of source and $\mathrm{P}=$ position index. Of these two main types of glare, disability glare creates the most visual problems because the scattering of light reduces the luminance contrast and interferes with normal vis- ibility. In normal eyes, the cornea contributes $30 \%$ of intraocular light scatter and the lens $70 \%$ while the aqueous and vitreous contribute less than $1 \%{ }^{4}$. The resultant sensitivity to glare increases with increasing age due to the scattering of light in the cornea and/or lens. Also, subjects with corneal oedema and cataracts will exhibit increased sensitivity to glare ${ }^{4}$.

Glare recovery is the rapidity with which the subject's visual functioning returns to what it was before the glare was encountered and is measured by exposing subjects to a bright bleaching light and then measuring the amount of time necessary to recover sight of a target. Therefore, the shorter the recovery time, the faster the subject is able to recover good vision after the glare stimulus has been stopped. Factors such as crystalline lens optical density, photopigment regeneration and aberrations determine glare recovery time ${ }^{5}$. A denser lens absorbs more of the bleaching light, leading to less isomerization of photopigments; hence, less photopigment needs to regenerate to restore visual function. A recent study ${ }^{6}$ has shown that subjects implanted with yellow intraocular lenses (AcrySof natural lens) could withstand significantly more glare light $(t=2.06 ; p<0.02)$ than subjects with clear intraocular lens (IOL). However, there was no statistically significant difference in photostress (glare) recovery times between subjects with clear intraocular lens and those with the AcrySof natural lens $(p<0.32)$. The authors concluded that subjects with the AcrySof natural lens (which absorbs high-energy short-wave energy) absorbed more of the bleaching light than the subjects with the clear IOL implants. Therefore the subjects with the clear IOL implants required to regenerate the most photopigments to regain sight of the target. Rekas et al7 compared higher order aberrations with spherical and aspherical IOLs compared to normal phakic eyes. The study found that in the case of coma aberrations, there was a statistically significant difference between spheric AcrySof and aspheric AcrySof $(p<0.005)$ and between spheric AcrySof and natural crystalline lenses $(p<0.005)$. Spherical aberrations were also significantly different between spheric and aspheric AcrySof group $(p<0.05)$. The study concluded that the AcrySof group resulted in higher aberrations relative to both the natural lens population and eyes after aspheric AcrySof group implantation.

Night vision and glare vision thresholds as well 
as recovery time measures appear to be of some significance and may show some association with visual degradation associated with night driving ${ }^{8}$. West et $a l^{9}$ reported recovery time to predict self-restriction in driving behaviour. Mesopic contrast sensitivity (contrast created due to a difference between object and background in low luminance or low light intensity) and glare recovery have been reported to diminish with age and after photorefractive keratectomy for myopia $^{10,11}$. Hansraj ${ }^{12}$ has reported that night vision and glare vision thresholds of myopes were reduced following LASIK surgery. Kurtev and Given ${ }^{13}$ compared glare recovery times in myopic subjects and emmetropes and concluded that myopes had longer glare recovery times and were more susceptible to glare than emmetropes. However, the authors did not provide an explanation for this finding. While it has been established that glare recovery time in myopic subjects is longer than in emmetropes, the literature lacks comparative data on myopic and hyperopic eyes. The purpose of this study was therefore to compare night vision and glare vision thresholds and recovery times in gender, race, age and power-matched optically compensated spherical myopic and hyperopic eyes.

\section{Methodology}

Following research and ethics approval, one thousand two hundred and fifty three students from the University of KwaZulu-Natal were screened with a battery of tests which included visual acuity measurements using the LogMAR chart, cover tests, autorefraction and subjective refraction. Ocular health was assessed with an ophthalmoscope, a slit lamp biomicroscope and an Amsler grid. All subjects with previous ocular surgery, contact lens wearers, subjects on any medication and those exhibiting known systemic and ocular pathologies, dry eyes or abnormalities of the precorneal tear film were excluded from the main study. Finally, eyes with astigmatism greater than $0.25 \mathrm{D}$, as determined by the subjective refraction, were excluded from the main study in order to have eyes with spherical errors with minimal or no astigmatism needed for this study. Only Black students were selected to participate in the study in order to minimize the differences in iris pigmentation. Also, only male subjects were recruited to minimize pupil- lary size differences. Written informed consent was obtained from all participants after the nature of the study was explained to them. The screening exercise was conducted by final year optometry students under the supervision of twelve optometrists at the University of KwaZulu-Natal Eye Clinic. Only eighty eight spherical ametropic eyes (44 spherical myopes and 44 spherical hyperopes as per criteria defined above) that satisfied the full inclusion criteria were included in the experimental groups. The 44 spherical myopic eyes and 44 spherical hyperopic eyes were obtained from 31 subjects with myopia and 39 subjects with hyperopia who met the inclusion criteria. The 70 subjects were optically compensated to achieve visual acuity of $6 / 6$ or better monocularly. They were instructed not to take alcohol or any intoxicating substance two days before the experimental tests.

All experimental tests were conducted with a Night Sight Meter (ISO Optical). To ensure maximum co-operation, attention and understanding of the procedures, a practice trial was performed for all the subjects prior to the main experimental data collection. The Night Sight Meter is designed to avoid instrument myopia and simulates conditions similar to those at night. The instrument was placed on a table in a dark room without windows to avoid surface reflections. During the testing, the subject viewed 15 Landolt C optotypes arranged in four orientations, which passed through a diamond shaped opening in the upper left corner of the instrument at a rate of 45 Landolt C's per minute. Two 6 Watt 115 Volt lamps provided target illumination in the instrument and the amount of light on the target was controlled by a rheostat. Glare recovery time was measured with a light emitting diode digital display timer linked to a touch time stop switch. Subjects were regularly reminded to keep fixation on the Landolt $C$ optotype and to avoid direct fixation on the glare source. Each subject was made to dark adapt for five minutes before the measurements as specified in the manual of the tester (ISO Optical). Night vision thresholds, glare vision thresholds and recovery times were subsequently measured monocularly with the best clear compensating glass lens in a trial frame. The lenses used were from the same manufacturer and each had a refractive index of 1.533. Prior to the tests, all the lenses were cleaned with Lensbrite (Peca products, USA) to remove finger prints and dust particles. Four readings were taken 
for each eye and averaged for each of the above tests. The procedure was then repeated for the fellow eye (if it met the criteria of minimal or no astigmatism as determined by the refraction tests) ten minutes after the first test.

\section{Measurement of night vision threshold}

The subject was instructed to look at the Landolt $\mathrm{C}$ optotype and report the orientation of its opening while the examiner decreased the illumination by one unit from $100 \mathrm{~cd} / \mathrm{m}^{2}$ until the subject incorrectly identified the optotype or gave up. This procedure was done monocularly on both myopic and hyperopic eyes wearing their best compensated prescription as determined from subjective refraction.

\section{Measurement of glare vision threshold}

This was measured by switching the glare light on and the subject was instructed to call out the orientation of the Landolt $\mathrm{C}$ while the examiner moved the dial to decrease illumination by one unit at a time from $100 \mathrm{~cd} / \mathrm{m}^{2}$ until the subject started missing the optotypes. The glare vision threshold value was recorded as the minimum amount of lighting with the glare source on required to detect and correctly identify the orientation of the target. Again, this procedure was performed monocularly on myopic and hyperopic subjects wearing their best compensated prescription.

\section{Measurement of glare recovery time}

Glare recovery measurement was done by setting the rheostat grating to the average of the night vision threshold determined in the first test (night vision threshold). The subject was reminded about the touch timer stop switch which the subject was made aware of in the beginning of the test. The glare source was switched off at the end of the 10 seconds exposure period and the timer started running automatically. The subject was instructed to report as soon as he could detect the orientation of the Landolt $\mathrm{C}$ after the removal of the glare source. At that point, the subject was asked to call out the orientation of the Landolt C's. The examiner then read off and recorded the glare recovery time (in seconds) from the digital display timer on the instrument. This measurement was done monocularly on myopic and hyperopic eyes with their best compensated prescription. The aver- age night vision thresholds, glare vision thresholds and glare recovery times were then categorized based on the values as specified in the manual of the tester (ISO Optical) (Table 1).

Table 1: Categorization of Night Sight Meter readings (ISO Optical)

\begin{tabular}{|l|c|c|c|}
\hline RATING & $\begin{array}{l}\text { Night } \\
\text { vision } \\
\text { threshold } \\
\left(\mathrm{cd} / \mathrm{m}^{2}\right)\end{array}$ & $\begin{array}{l}\text { Glare vision } \\
\text { threshold } \\
\left(\mathrm{cd} / \mathrm{m}^{2}\right)\end{array}$ & $\begin{array}{l}\text { Glare re- } \\
\text { covery time } \\
(\mathrm{secs})\end{array}$ \\
\hline A - GOOD & $0-15$ & $0-30$ & $0-1.5$ \\
\hline $\begin{array}{l}\text { B -ABOVE } \\
\text { AVERAGE }\end{array}$ & $16-20$ & $31-40$ & $1.6-2.5$ \\
\hline C-AVERAGE & $21-25$ & $41-55$ & $2.6-4$ \\
\hline $\begin{array}{l}\text { D - BELOW } \\
\text { AVERAGE }\end{array}$ & $26-35$ & $56-76$ & $4.1-6$ \\
\hline E-POOR & $>35$ & $>77$ & $>6$ \\
\hline
\end{tabular}

Statistical analysis was performed using descriptive statistics, the two-sample $t$-test and Pearson correlation coefficients of the SPSS programme (version 15.0). The data collected was analyzed by a biostatistician from the University of KwaZulu-Natal's Faculty of Health Sciences. The level of statistical significance was set at $p<0.05$.

\section{Results}

Data was analyzed per eye as subjective refractions were obtained for each eye individually. Distance spectacle refractive corrections of the myopic eyes ranged from $-0.50 \mathrm{D}$ to $-4.50 \mathrm{D}$ (mean $=-2.15$ $\mathrm{D} \pm 1.41$ ) while those of hyperopic eyes ranged from $0.50 \mathrm{D}$ to $4.00 \mathrm{D}($ mean $=1.76 \mathrm{D} \pm 1.22)$. Night vision thresholds for myopic eyes were higher (range = $23 \mathrm{~cd} / \mathrm{m}^{2}$ to $42 \mathrm{~cd} / \mathrm{m}^{2}$, mean $\left.=32 \mathrm{~cd} / \mathrm{m}^{2} \pm 4.69\right)$ than for hyperopic eyes (range $=18 \mathrm{~cd} / \mathrm{m}^{2}$ to $37 \mathrm{~cd} / \mathrm{m}^{2}$, mean $\left.=28.97 \mathrm{~cd} / \mathrm{m}^{2} \pm 4.90\right)$ as seen in Figure 1 . The difference between the mean night threshold of myopic and hyperopic eyes was statistically significant $(p=0.002)$.

Glare vision thresholds for myopic eyes ranged from $53 \mathrm{~cd} / \mathrm{m}^{2}$ to $78 \mathrm{~cd} / \mathrm{m}^{2}$, with a mean of $64 \mathrm{~cd} / \mathrm{m}^{2} \pm$ 5.82. For hyperopic eyes, glare threshold ranged from $32 \mathrm{~cd} / \mathrm{m}^{2}$ to $59 \mathrm{~cd} / \mathrm{m}^{2}$, with a mean of $44.84 \mathrm{~cd} / \mathrm{m}^{2} \pm$ 5.69 (see Figure 1). The mean glare vision threshold for myopic eyes was higher than for the hyperopic 


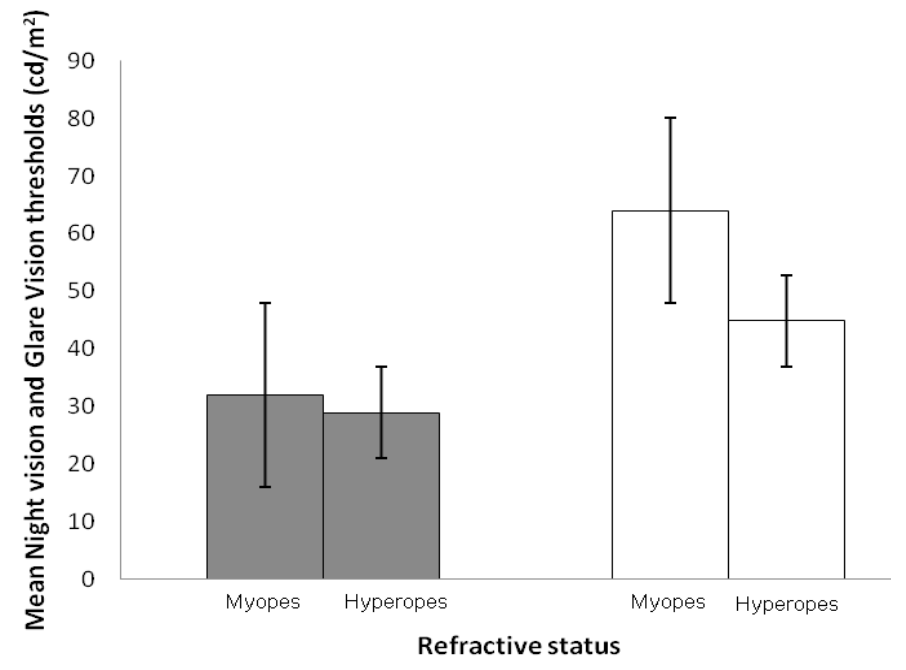

Figure 1: Showing the mean night vision (grey bars) and glare vision (clear bars) thresholds of the myopic and hyperopic eyes. The grey bars show that the mean night vision threshold of the myopic eyes is higher than that of the hyperopic eyes. Also, the clear bars show that the mean glare vision threshold of the myopic eyes is higher than that of the hyperopic eyes.

eyes and the difference was statistically significant ( $p$ $<0.05)$.

Glare recovery times for myopic eyes ranged from $0.45 \mathrm{~s}$ to $3.10 \mathrm{~s}$, with a mean of $1.41 \mathrm{~s} \pm 0.77$ while that of hyperopic eyes ranged from $0.30 \mathrm{~s}$ to $2.25 \mathrm{~s}$, with a mean of $1.04 \mathrm{~s} \pm 0.65$. Also, the differences between the mean values were statistically significant $(p<0.05)$ for myopic and hyperopic eyes respectively (see Figure 2).

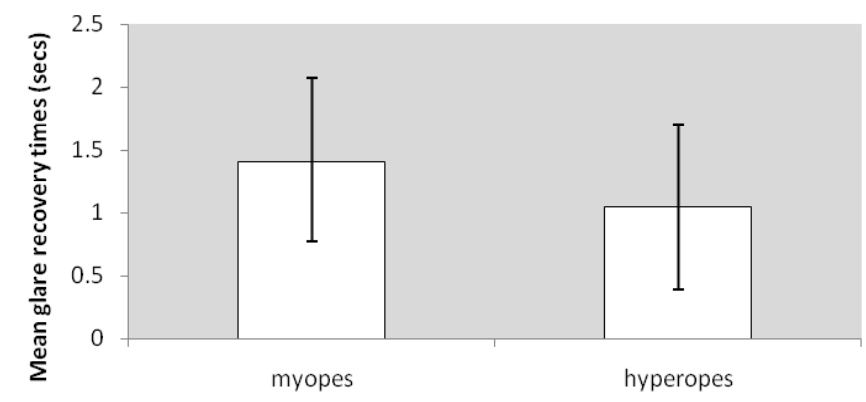

Figure 2: Mean glare recovery times of myopic and hyperopic eyes.

The scatter plots for glare recovery against the magnitude of myopia are shown in Figure 3. The regression line shows a linear positive correlation between glare recovery time and the magnitude of myopia $(r=0.93, p<0.05)$. The regression equation for the scatter plot is $y=0.527 x+0.3369$.

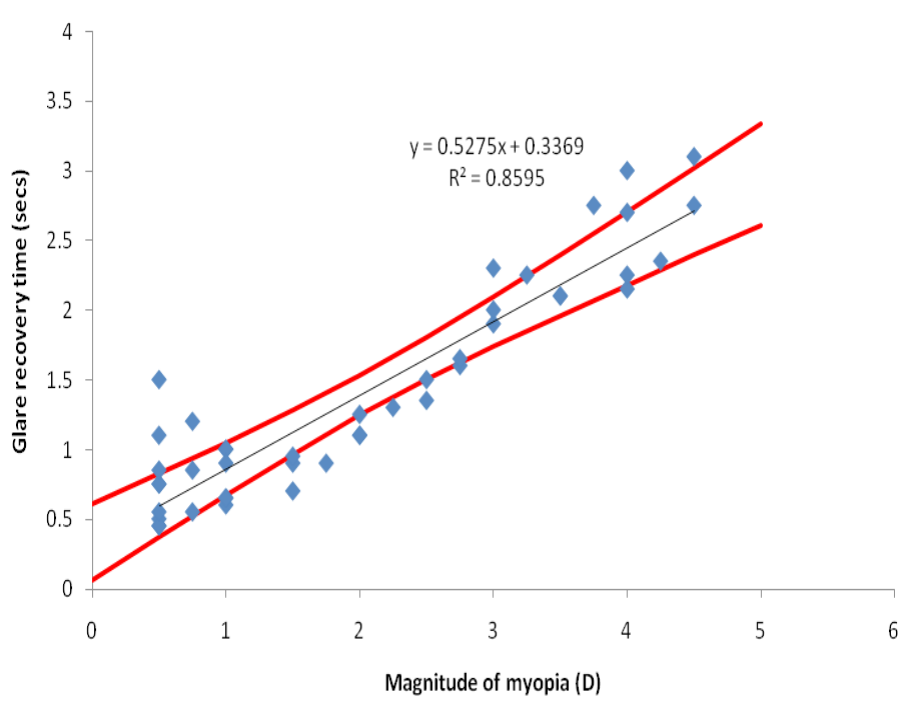

Figure 3: The scatter plots for the glare recovery time plotted against the magnitude of myopia. The solid straight line is the linear regression to the data and the red lines represent the $95 \%$ confidence regions. All of the 44 data points are not shown due to the fact that most of the coordinates are the same and the points therefore, lie on each other.

A scatter plot for glare recovery time and the magnitude of hyperopia is illustrated in Figure 4. The graph shows a negative relation between glare recovery time and the magnitude of hyperopia $(r=-0.76$, $p<0.05)$, with regression equation $y=-0.4061 x+$ 1.7642 .

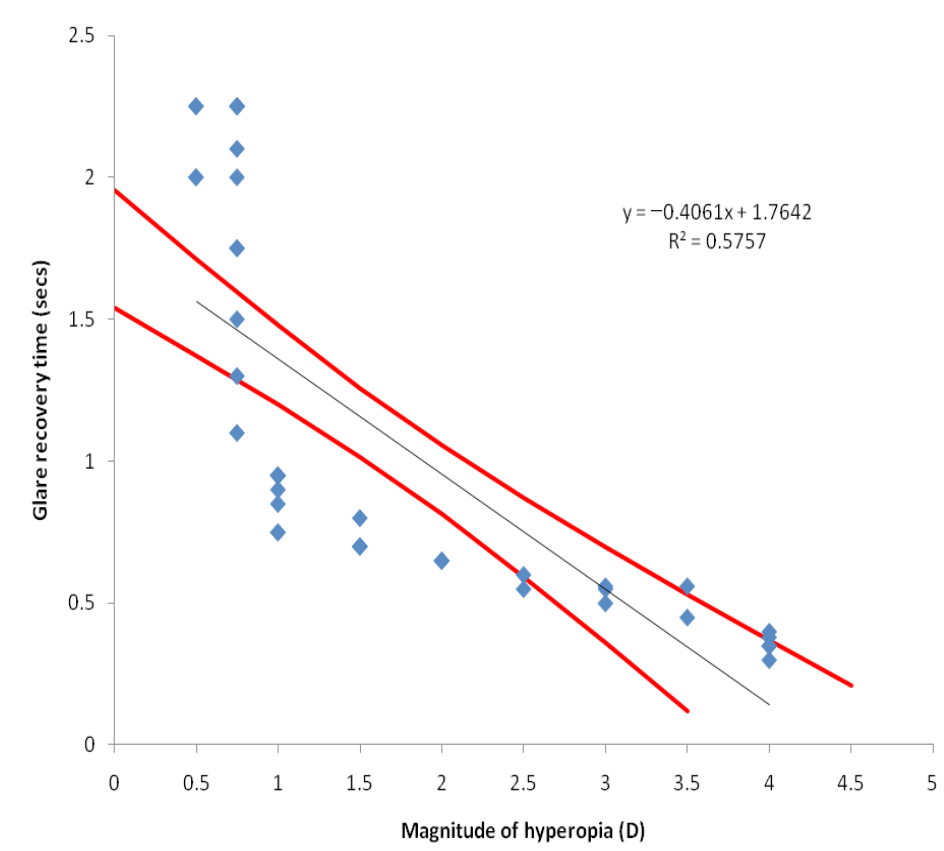

Figure 4: The scatter plots for the glare recovery time and magnitude of hyperopia. The solid straight line is the linear regression to the data and the red lines represent the $95 \%$ confidence regions. Again, most of the coordinates are the same; hence many points overlap. 


\section{Discussion}

The higher the night vision threshold, the poorer the subject's vision under low illumination. Both myopic and hyperopic eyes had night vision thresholds that fell in the category of below average, indicating poor ability to see at night. However, a comparison of the means of night vision thresholds for the myopic eyes $\left(32 \mathrm{~cd} / \mathrm{m}^{2} \pm 4.69\right)$ and hyperopic eyes $(28.97 \mathrm{~cd} /$ $\left.\mathrm{m}^{2} \pm 4.90\right)$ suggested a statistically significant difference $(p=0.002)$. The large pupil diameters in myopes allow more light to cause a veil over the fovea which changes its adaptation or sensitivity to visual stimu$1 i^{14,15}$. Therefore, at night, myopic subjects will complain more than hyperopes (of similar age and ocular status) of poor performance and reduced visibility in certain visual tasks such as driving in spite of normal compensated visual acuity.

As in the night vision threshold, the higher the glare vision threshold, the poorer is the subject's night vision in the presence of a glare source. Myopic eyes had mean glare vision thresholds that fell in the category of below average $\left(64 \mathrm{~cd} / \mathrm{m}^{2} \pm 5.82\right)$ while hyperopic eyes had mean glare vision threshold that fell in the category of average $\left(44.84 \mathrm{~cd} / \mathrm{m}^{2} \pm 5.69\right)$. A comparison of the mean glare threshold values for the two groups suggested that the differences were statistically significant $(p<0.05)$. These findings indicate that glare created more visual problems for myopic eyes than hyperopic eyes and therefore hyperopic eyes appear to have better ability to see in the presence of glare. Again, spherical aberrations of the dilated pupil in myopes and fifth order aberrations such as coma could be responsible for these results ${ }^{14-18}$. Glare is known to originate from an increase in light-scattering in the eye's optical media ${ }^{14}$. This results in a veil of stray light over the retina, which in turn reduces the contrast of the retinal image ${ }^{15}$.

The shorter the recovery time, the faster is the subject's ability to regain good vision after the disruption of vision due to a veiling luminance. In this study, good recovery times were recorded for both myopic and hyperopic eyes (according to the categorization). However, the mean value for myopic eyes $(1.41 \mathrm{~s} \pm$ 0.77 ) was significantly higher than those of the hyperopic eyes (1.04 $\mathrm{s} \pm 0.65)$, with a very small $p$-value. As with night and glare thresholds results, this is possibly due to the fact that myopes have large pupil di- ameters which cause optical and retinal image degradation induced by aberrations. Charman ${ }^{16}$ found that due to large pupils in myopes, aberration levels and associated retinal blur was larger than those of the rest of the population. Collins et al, ${ }^{17}$ using an objective double-pass aberroscope, reported high variability in monochromatic aberrations in myopic eyes with at least one third of the myopic eyes having aberrations that were so large that no grid image was observable. In the present study, there appeared to be a linear increase in recovery times with an increase in the magnitude of myopia ( $r=0.93, p=0.00$ ) (Figure 3). Also, the figure, $\left(\mathrm{R}^{2}=0.8595\right)$ suggests a linear relationship between the two variables. On the contrary, there was a decrease in glare recovery times with an increase in the magnitude of hyperopia $(\mathrm{r}=-0.76, \mathrm{p}=0.00)$ (Figure 5). Similarly, $\mathrm{R}^{2}$ was 0.5757 , indicating a linear relationship. While it appears that the data points in the range of optic magnitude of the defect $0.5 \mathrm{D}$ to $1 \mathrm{D}$ in both myopic and hyperopic eyes might have created insignificant effects, the linear regressions $(r=0.93, p=0.00$ for myopes and $r=-0.76$, $p=0.00$ for hyperopes) are still highly significant and uniform (Figures 3 and 4). Marcos et al18 reported significantly increased third-order aberrations in young myopes $(r=0.82, p<0.0001)$. Furthermore, the study by Marcos et al18 showed that both fourth and higher order aberrations increased with the magnitude of myopia, although not significantly $(r=0.33$, $p=0.15 ; r=0.32, p=0.16$ respectively). The results on recovery times imply that myopic drivers of similar age and ocular status will often complain more than hyperopes about night driving difficulties due to glare from oncoming traffic lights. It is recommended that myopes be prescribed with lenses that have glare reducing effects such as anti-reflection coating to reduce the potential deleterious effects of glare. Anti-reflection coating has been reported to significantly reduce recovery times, allowing the subjects to recover good vision after exposure to a glare stimulus ${ }^{19}$.

Reduced ability to see under conditions of low illumination and against glare as well as recovery time are major impediments during night driving. The pupil-related aberrations in the myopic eye's optical media result in the degradation of the image quality ${ }^{14,15}$. Several studies ${ }^{20-23}$ have also reported that myopia is accompanied by moderate increase in aberrations while others $^{24,25}$ did not find an increase. For example, 
Paquin $^{20}$ using an objective Shack-Hartmann aberrometer reported worse optical quality in myopic eyes due to aberrations. Coma aberrations were also found to be more frequent in high myopia. He et al ${ }^{21}$ measured aberrations in 146 young adults and found that myopes had slightly larger combined fourth-order and higher aberrations than emmetropes $(p<0.01)$. Kirwan et $a l^{26}$ found paediatric hyperopic eyes to have lower levels of higher-order aberrations than paediatric myopic eyes. In contrast to the above studies, Llorente et al ${ }^{27}$ found higher amounts of total spherical aberrations, third and higher order aberrations (pupil dilation $=6.5 \mathrm{~mm}$ ) in hyperopic compared with myopic subjects. Internal spherical aberrations were however, not significantly different between hyperopic and myopic eyes. Martinez et al ${ }^{28}$ reported high levels of spherical aberrations in hyperopic eyes in comparison to emmetropic eyes of Caucasian children aged 6 to 12 years old. The inconsistent results in these various studies can be attributed to differences in age, ethnicity and methodologies used for the measurement of aberrations. Also, the differences in the anatomical characteristics of the eyes such as corneal asphericity and crystalline lens features could have been a factor.

It has also been reported that compensation of spherical aberrations by the internal ocular optics is better in hyperopic eyes ${ }^{29,30}$. Furthermore, with the increased pupil diameters in myopes, the periphery of the lens scatters light more strongly than the central parts of the lens, further increasing aberrations leading to image degradation and therefore longer thresholds and recovery times ${ }^{15}$. It is also widely accepted that spherical myopic eyes have characteristically longer axial length than hyperopic ones ${ }^{31}$. Hence, when axial refractive errors are corrected with spectacle lenses, spherical aberrations may increase with increasing amount of myopia, and therefore better controlled studies that measure axial length and higher degrees of ametropia to compare thresholds and recovery times are warranted. Reiner et $a l^{32}$ and Shimada et $a l^{33}$ also suggest evidence of decreased choroidal and retinal blood flow in myopia (even though at a sub-clinical level), which might lead to disruption of visual performance and prolonged thresholds and recovery times.

\section{Conclusion}

It is important to realize that myopic and hyperopic eyes could perform differently under different lighting conditions especially under glare conditions. Night vision and glare vision thresholds of spherical myopic eyes were significantly higher than those of spherical hyperopic eyes. This indicates that spherical myopic eyes might have greater difficulty seeing in conditions of low illumination and in the presence of glare compared to the hyperopic eyes from subjects of similar gender, race, age and ocular status. Also, spherical myopic eyes took longer time to regain vision after exposure to a glare stimulus. A limitation of this study is that findings were based on information obtained from only spherical myopic and spherical hyperopic eyes selected from one gender, one racial group and a young population. It can therefore not be generalized for all myopic and hyperopic eyes with regards to thresholds and recovery time. An additional limitation of this study is that the dominant eyes were not determined and pupil diameters were not measured in each group. Eye dominancy and pupil diameters may influence findings in this type of study. It is recommended that future studies be conducted in a diverse population in terms of race and gender so that comparative inferences can be drawn.

\section{Acknowledgements}

I wish to acknowledge Professor A Kurtev of Saba University School of Medicine in Netherlands and $\mathrm{Mr}$ SD Mathebula of the University of Limpopo for their assistance. I also thank Professor OA Oduntan, Dr R Hansraj and Mr MR Kobe of the University of KwaZulu-Natal for their helpful comments in preparing this manuscript.

\section{References}

1. Fan-Paul NI, Li J, Miller JS, Florakis GJ. Night vision disturbances after corneal refractive surgery. Surv Ophthal 200247 533-546.

2. Stringham JM, Hammond BR. Macular pigment and visual performance under glare conditions. Optom Vis Sci $2008 \mathbf{8 5}$ 82-88.

3. North RV. Work and the eye. Butterworth-Heinemann, London, 2001 pp112-119. 
4. Elliot BD. Contrast sensitivity and glare testing. In: Benjamin WJ (ed) Borish's clinical refraction. Saunders, Philadelphia, 1998 pp 203-241.

5. Stringham JM, Hammond BR. The glare hypothesis of macular pigment function. Optom Vis Sci 200784 859-864.

6. Hammond BR, Bernstein B, Dong J. The effect of the AcrySof natural lens on glare disability and photostress. Am J Ophthalmol 2009148 272-276.

7. Rekas M, Krix-Jachym K, Zelichowska B. Comparison of higher order aberrations with spherical and aspheric IOLs compared to normal phakic eyes. Eur J Ophthalmol 2008 18 728-732.

8. Puell MC, Palomo C, Sanchez-Ramos C, Villena C. Mesopic contrast sensitivity in the presence or absence of glare in a large driver population. Graefes Arch Clin Exp Ophthalmol 2004242 755-61.

9. West GC, Gildengorin G, Haegerstrom-Portnoy G, Schneck ME, Brabyn JA. Vision and driving self-restriction in older adults. J Am Geriatr 200351 1348-1355.

10. Nagy ZZ, Munkacsy G, Krueger R. Changes in mesopic vision after photorefractive keratectomy for myopia. $J$ Refract Surg 200218 249-252.

11. Schlote T, Kriegerrowski M, Bende T, Derse M, Thiel HJ, Jean B. Mesopic vision in myopia corrected by photorefractive keratectomy, soft contact lenses, and spectacles. J Cat Refract Surg 199723 718-725.

12. Hansraj R. Night vision of the post-LASIK myope. S Afr Optom 200766 141-149.

13. Kurtev A, Given J. Glare recovery time in myopes. 27th ECVP, Perception (Suppl) 200433128.

14. Franssen L, Taberneno J, Coppens JE, van den Berg TJTP. Pupil size and retinal straylight in the normal eye. Invest Ophthalmol Vis Sci 200748 2375-2382.

15. Westheimer G. Directional sensitivity of the retina: 75 years of Stiles-Crawford effect. Proc R Soc B 20082752777 2786.

16. Charman WN. Aberrations and myopia. Ophthal Physiol Opt 200525 285-301.

17. Collins M, Wildsoet C, Atchison D. Monochromatic aberrations and myopia. Vis Res 199535 1157-1163.

18. Marcos S, Moreno-Barriuso E, Llorente L, Navarro R, Barbero S. Do myopic eyes suffer from larger amount of aberrations? In: Thorn F, Troilo D, Gwiazda J, eds. Myopia 2000: Proceedings of the VIII International Conference on Myopia. Boston: The New England College of Optometry, 2000, pp 118-121.

19. Mashige KP, Thathane NP, Kader F, Nyandoro GD, Sultan AA. The effect of anti-reflection coating on glare threshold and recovery under scotopic conditions. S Afr Optom 2008 67 68-76.

20. Paquin M, Hamam H, Simonet P. Objective measurement of optical aberrations in myopic eyes. Optom Vis Sci 2002 79 285-291.

21. He J, Sun P, Held R, Thorn F, Sun X, Gwiazda J. Wavefront aberrations in eyes of emmetropic and moderately myopic school children and young adults. Vis Res 2002421063 1070 .
22. Buehren T, Collins MJ, Carney LG. Near work induced wavefront aberrations in myopia. Vis Res 200545 12971312.

23. Mathur A, Atchison DA, Charman WN. Myopia and peripheral ocular aberrations. $J$ Vis 2009 15 1-12.

24. Atchison DA, Schmid KL, Pritchard N. Neural and optical limits to visual performance in myopia. Vis Res 200646 3707-3722.

25. Zadok D, Levy Y, Segal O, Barkana Y, Morad Y, Avni I. Ocular higher order aberrations in myopia and skiascopic wavefront repeatability. J Cat Refract Surg 200531 11281132.

26. Kirwan C, O'Keefe M, Soeldner H. Higher-order aberrations in children. Am J Ophthalmol 2006141 67-70.

27. Llorente L, Barbero S, Cano D, Dorronsoro C, Marcos S. Myopic versus hyperopic eyes: Axial length, corneal shape and optical aberrations. J Vis 20045 288-298.

28. Martinez AA, Sankaridurg PR, Naduvilath TJ, Mitchell P. Monochromatic aberrations in hyperopic and emmetropic children. $J$ Vis 20099 1-14.

29. Artal P, Benito A, Taberneno J. The human eye is an example of robust optical design. J Vis 20066 1-7.

30. Benito A, Artal P. Compensation of corneal aberrations by the internal optics of the eye is better in hyperopic eyes. Invest Ophthalmol Vis Sci 200445 176. [Abstract]

31. Cheng X, Bradley A, Hong X, Thibos LN. Relationship between refractive error and monochromatic aberrations of the eye. Optom Vis Sci 200380 43-49.

32. Reiner A, Shih YF, Fitzgerald ME. The relationship of choroidal blood flow and accommodation to the control of ocular growth. Vis Res 199535 1227-1245.

33. Shimada N, Ohno-Matsui K, Harino S, Yoshida T, Yasuzumi K, Kojima A. Reduction in retinal blood glow in high myopia. Graefes Arch Clin Exp Ophthalmol 2004242 284288. 